\title{
PERKAITAN ANTARA CORAK ORIENTASI MATLAMAT DAN TAHAP KEAGRESIFAN PEMAIN BOLA BALING BAWAH 18
}

\author{
Siti Aishah Md Yusop, Shaharudin Abd Aziz \& Nelfianty Mohd Rasyid \\ Fakulti Sains Sukan dan Kejurulatihan, Universiti Pendidikan Sultan Idris, Tanjung Malim, \\ Perak, Malaysia
}

Jurnal Sains Sukan dan Pendidikan Jasmani 7(2): 34-44, Received: 1 September 2018, Accepted: 1 October 2018

\begin{abstract}
Kajian ini bertujuan untuk mengenal pasti perkaitan antara corak orientasi matlamat dan keagresifan terhadap pemain bola baling bawah 18 tahun, Negeri Sembilan. Rekabentuk kajian adalah kaedah tinjauan menggunakan soal selidik Task and Ego Orientation in Sport Questionaire (TEOSQ) dan The Judgement About Moral Behavior in Youth Sport Questionaire (JAMBYSQ). Responden kajian adalah atlet bola baling bawah 18 tahun yang mewakili 8 buah daerah di Negeri Sembilan ( $n=192,96$ lelaki dan 96 perempuan). Data dianalisis menggunakan statistik deskriptif (peratus, kekerapan, min dan sisihan piawai) dan statistik inferensi (ujian-t) dan korelasi. Dapatan kajian menunjukkan corak orientasi tugasan atlet bola baling perempuan adalah lebih tinggi berbanding atlet lelaki bagi kedua-dua orientasi tugasan dan ego. Hasil dapatan ujian-t menunjukkan atlet bola baling perempuan mempunyai tahap kebimbangan kognitif dan somatik yang lebih tinggi berbanding atlet lelaki. Namun dari aspek tahap keagresifan pula, dapatan kajian menunjukkan atlet perempuan lebih cenderung untuk melakukan tindakan agresif berbanding atlet bola baling lelaki. Kesimpulannya, hasil kajian mendapati bahawa terdapat hubungan yang signifikan di antara orientasi matlamat dan keagresifan dalam kalangan atlet bola baling bawah 18. Secara tidak langsung, kajian ini dapat memberi justifikasi kepada atlet dan jurulatih tentang kepentingan orientasi matlamat. Jurulatih juga perlu lebih menumpukan perhatian yang lebih terhadap orientasi tugasan berbanding orientasi ego.
\end{abstract}

Kata kunci: orientasi matlamat, keagresifan, bola baling, atlet sekolah menengah 


\title{
RELATIONSHIP BETWEEN GOAL ORIENTATION AND AGGRESSIVENESS AMONG UNDER 18 HANDBALL PLAYERS
}

\begin{abstract}
The purpose of this study is to identify the relationship between goal orientation and aggressiveness among under 18 handball players in Negeri Sembilan. This study used survey method using Task and Ego Orientation in Sport Questionaire (TEOSQ) and The Judgement About Moral Behavior in Youth Sport Questionaire (JAMBYSQ). The respondents are the Under 18 handball players that represent eight districts in Negeri Sembilan $(n=192,96$ male and 96 females). Data were analyzed using descriptive statistics (percent, frequency, mean and standard deviation) and inferential statistics (t-test) and correlation. The findings showed that the orientation pattern of the female players were higher than the male players for both the task orientation and the ego. The results of the t-test showed that female handball players have higher levels of cognitive and somatic anxiety than male players. However, from the aspect of aggression, the findings showed that female players are more likely to show aggressive action compared to male. In conclusion, the findings showed that there was a significant relationship between goal orientation and aggression among under 18 handball players. Indirectly, this study stressed the importance of goal orientation. Coaches also need to put more focus on the task-orientation compared to ego-orientation.
\end{abstract}

Keywords: goal orientation, aggressiveness, handball, secondary school athletes

\section{PENGENALAN}

Sukan bola baling merupakan sebuah sukan kontak kerana ia merupakan permainan yang sangat pantas dan aggresif. Setiap pasukan akan berusaha untuk mendapatkan bola bagi membolehkan mereka membuat jaringan gol bagi menambah skor dan mengalahkan pihak lawan. Menurut James \& David (2012), sukan bola baling merupakan sukan yang mempunyai risiko kecederaan yang sangat tinggi. Bersesuaian dengan kajian daripada Junge, Sielaff \& Engelbrecth (2009) iaitu berdasarkan data yang diambil daripada sukan Olimpik Beijing menunjukkan kadar kecederaan atlet yang tinggi adalah daripada permainan bola baling iaitu 92 peratus kecederaan berlaku ketika berlangsungnya perlawanan bola baling.

Setiap pemain pasti mempunyai orientasi matlamat ketika menceburkan diri dalam bidang sukan mahupun bertanding dalam sesuatu acara yang dipertandingkan. Pemain ini lebih akan sentiasa menonjolkan diri dan berusaha dengan pelbagai kaedah, cara, teknik mahupun taktik bagi memastikan mereka mencapai apa yang dihasratkan. Gill (2000) dalam bukunya menyatakan corak orientasi matlamat adalah bergantung kepada bagaimana seseorang itu mendefinisikan kejayaannya. Individu yang berorientasikan tugasan, akan tertumpu kepada perbandingan 
pencapaian dengan tahap kemajuan diri individu itu sendiri. Manakala individu yang berlandaskan ego pula akan lebih cenderung untuk melakukan tindakan agresif (Weinberg \& Gould, 2003).

Istilah keagresifan sering dikaitkan dengan perlakuan yang negatif dan bertentangan dengan etika kesukanan (Silva, 1992). Adakalanya keagresifan itu merupakan satu keperluan dalam diri atlet dalam mencapai kejayaan, namun seringkali keagresifan itu dikaitkan dengan tingkah laku yang tidak diingini seperti membentes pihak lawan dengan sengaja, provokasi terhadap pihak lawan, dan sebagainya. Hal ini biasanya terjadi pada waktu kemuncak perlawanan dimana pihak lawan mendahului mata dalam perlawanan. Situasi ini boleh mengganggu kelancaran sepanjang permainan dan mengakibatkan pemain-pemain hilang fokus untuk bermain.

Oleh yang demikian, tumpuan kajian ini adalah untuk mengkaji perkaitan antara corak orientasi matlamat dan keagresifan terhadap pemain bola baling bawah 18 tahun. Isu yang diberi perhatian dalam kajian ini adalah mengkaji apakah corak orientasi matlamat dalam kalangan atlet dan punca yang mendorong atlet melakukan keagresifan yang sedemikian. Kajian ini juga bertujuan untuk mengkaji perkaitan antara kedua-dua pembolehubah terhadap atlet dan bagaimana atlet membuat sesuatu keputusan terutama dalam situasi-situasi genting semasa pertandingan. Bersesuaian dengan Nathan (2016) menyatakan membuat keputusan adalah "apa yang hendak dilalukan semasa permainan”. Pengetahuan terhadap kedua-dua pembolehubah ini amat penting dalam pembangunan sukan yang mula dimainkan dari akar umbi sehinggalah golongan elit agar dapat menjulang semua sukan di Malaysia ke persada dunia.

\section{METODOLOGI}

\section{Rekabentuk kajian}

Kajian ini berbentuk kaedah tinjauan dengan menggunakan borang soal selidik berkaitan corak orientasi matlamat 'Task and Ego Orientation in Sports Questionaire (TEOSQ)' dan tahap keagresifan 'The Judgements About Moral Behavior in Youth Sport (JAMBYSQ)

\section{Pemilihan responden}

Responden kajian terdiri daripada pemain bola baling Negeri Sembilan yang terdiri daripada 8 buah daerah iaitu daerah Seremban 1, Seremban 2, Jempol, Jelebu, Rembau, Tampin, Kuala Pilah dan Port Dickson. Kumpulan responden 1 terdiri daripada 96 orang atlet bola baling bawah 18 tahun bagi kategori perempuan. Kumpulan responden 2 terdiri daripada 96 orang atlet bola baling bawah 18 tahun bagi kategori lelaki. Secara keseluruhannya, seramai 192 orang atlet bola baling telah menyertai kajian ini.

\section{Instrumen Kajian}

Instrumen yang sering digunakan untuk mengukur komponen efektif seseorang seperti pendapat, tingkah laku, personaliti, motivasi, minat, masalah peribadi, serta perasaan adalah dengan menggunakan pensil dan kertas (Baumgaartner \& Hensley, 2006). Oleh yang demikian, ujian untuk kajian ini adalah menggunakan borang soal selidik yang mempunyai 3 bahagian iaitu 
bahagian (a) maklumat diri, bahagian (b) corak orientasi matlamat dab bahagian (c) tahap keagresifan.

Bahagian A :

Untuk mengetahui latar belakang peribadi dan latar belakang penglibatan responden dalam sukan bola baling. Maklumat dari faktor-faktor input responden disusun mengikut kategori seperti umur, jantina, bangsa dan bilangan tahun penglibatan dalam sukan bola baling.

\section{Bahagian B :}

Bahagian ini mengkaji corak orientasi matlamat. Borang soal selidik yang telah digunakan ialah Task and Ego Orientation in Sport Questionaire (TEOSQ ; Duda \& Nicholls, 1989). Shahrudin (1998), telah menterjemah borang soal selidik TEOSQ bagi kegunaan tempatan.

\section{Bahagian C:}

Bahagian ini terdiri daripada borang soal selidik untuk mengkaji tahap keagresifan. Borang soal selidik yang telah digunakan ialah The Judgement About Moral Behavior in Youth Sport Questionaire (JAMBYSQ ; Stephens, 1993 terjemahan Shaharudin, 1998). Borang soal selidik yang telah diedarkan kepada responden merupakan borang soal selidik yang telah diubahsuai oleh penyelidik untuk menonjolkan perlakuan agresif semasa perlawanan bola baling berlangsung sebagai gambaran untuk responden membayangkan situasi yang berlaku. Pengubahsuaian ini telah dipersetujui oleh pensyarah penilai, yang mempunyai kepakaran berkaitan tajuk keagresifan, dipersetujui Pengerusi Teknik Bola Baling Daerah Seremban 1, Pengerusi Teknik Bola Baling dan Pembangunan Sukan MSSNS, Negeri Sembilan serta seorang pengadil dan dua orang jurulatih yang bergiat aktif dalam sukan permainan bola baling. Contoh situasi yang diberikan ini telah di pecahkan mengikut jantina lelaki dan perempuan.

\section{Kaedah memproses dan menganalisis data}

Data yang diperolehi, diproses dan dianalisis menggunakan perisian Statistical Package For Social Science (SPSS). Hasil analisis dipersembahkan secara deskriptif seperti taburan frekuensi, peratusan, min dan sisihan piawai. Manakala inferensi pula adalah ujian t dan korelasi.

\section{DAPATAN KAJIAN}

\section{Corak orientasi matlamat}

Bagi mengenalpasti corak orientasi matlamat keseluruhan pemain bola baling lelaki dan perempuan, analisis min dan sisihan piawai telah digunakan. Analisis dalam jadual 1 menunjukkan min bagi corak orientasi tugasan pemain bola baling $(\mathrm{M}=3.24, \mathrm{SP}=0.37)$ adalah lebih tinggi berbanding corak orientasi ego $(\mathrm{M}=2.58, \mathrm{SP}=0.28)$. Analisis ujian-t tidak bersandar berdasarkan jadual 4 menunjukkan terdapat perbezaan yang signifikan bagi corak orientasi tugasan $\mathrm{t}=-6.95$ 
(190) $\mathrm{p}=0.00$. Min bagi orientasi tugasan dan ego bagi pemain bola baling bawah 18 adalah berbeza secara signifikan

Jadual 1: Analisis Min dan Sisihan Piawai Item Orientasi Matlamat

\begin{tabular}{lll}
\hline Corak Orentasi & $\mathbf{N}$ & Min(SP) \\
\hline Tugasan & 192 & $3.24(0.37)$ \\
Ego & 192 & $2.58(0.28)$ \\
\hline
\end{tabular}

Jadual 2: Analisis Min dan Sisihan Piawai Item Orientasi Matlamat bagi Pemain Bola Baling Lelaki Bawah 18 Tahun

\begin{tabular}{llc}
\hline Corak Orentasi & N & Min (SP) \\
\hline Tugasan & 96 & $3.07(0.32)$ \\
Ego & 96 & $2.53(0.30)$ \\
\hline
\end{tabular}

Analisis yang digunakan adalah min dan sisihan piawai serta ujian bagi mengenal pasti corak orientasi matlamat pemain bola baling lelaki. Analisis menunjukkan corak orientasi tugasan pemain bola baling lelaki $(\mathrm{M}=3.07, \mathrm{SP}=0.32)$ lebih tinggi berbanding corak orientasi ego $(\mathrm{M}=$ 2.53, SP =0.30). Ujian-t Sampel Tidak Bersandar menunjukkan bahawa nilai $\mathrm{t}=-6.95(190)=0.61$, $\mathrm{p}=0.00$ adalah signifikan.

Jadual 3: Analisis Min dan Sisihan Piawai Item Orientasi Matlamat bagi Pemain Bola Baling Perempuan Bawah 18 Tahun

\begin{tabular}{lll}
\hline Corak Orentasi & $\mathbf{N}$ & Min $(\mathbf{S P})$ \\
\hline Tugasan & 96 & $3.40(0.34)$ \\
Ego & 96 & $2.62(0.25)$ \\
\hline
\end{tabular}

Analisis yang digunakan merupakan analisis min dan sisihan piawai bagi mengenal pasti corak orientasi matlamat pemain bola baling perempuan. Analisis min menujukkan corak orientasi tugasan pemain bola baling perempuan $(\mathrm{M}=3.40, \mathrm{SP}=0.34)$ lebih tinggi berbanding corak orientasi ego $(\mathrm{M}=2.62, \mathrm{SP}=0.25)$. Ujian-t Sampel Tidak Bersandar menunjukkan bahawa nilai $\mathrm{t}=-2.42(190)=0.01, \mathrm{p}=0.02$ adalah signifikan. 
Jadual 4: Ujian -t Perbezaan Orientasi Tugasan

bagi Pemain Bola Baling Lelaki dan Perempuan Bawah 18 Tahun

\begin{tabular}{|c|c|c|c|c|c|c|}
\hline & & & Ujian & Levene's & Persamaan & Min \\
\hline & & \multicolumn{3}{|c|}{ Persamaan Varian } & \multicolumn{2}{|l|}{ Ujian -t } \\
\hline & & Nilai $F$ & Signifikan & $\mathbf{T}$ & $\begin{array}{l}\text { Darjah } \\
\text { Kebebasan }\end{array}$ & $\begin{array}{l}\text { Tahap } \\
\text { signifikan }\end{array}$ \\
\hline \multirow{2}{*}{ Jantina } & $\begin{array}{l}\text { Persamaan } \\
\text { Varian } \\
\text { Andaian }\end{array}$ & 0.27 & 0.61 & -6.95 & 190 & $0.00 *$ \\
\hline & $\begin{array}{l}\text { Persamaan } \\
\text { Varian } \\
\text { B/Andaian }\end{array}$ & & & -6.95 & 189.23 & $0.00 *$ \\
\hline
\end{tabular}

Bagi analisis statistik kaedah Ujian-t Sampel Tidak Bersandar menunjukkan bahawa nilai $\mathrm{t}=-6.95(190)=0.61, \mathrm{p}=0.00$ adalah signifikan. Keputusan ujian menunjukkan bahawa terdapat perbezaan yang signifikan dalam skor min orientasi matlamat tugasan diantara pemain bola baling perempuan $(\mathrm{M}=3.40, \mathrm{SD}=0.34)$ dan pemain lelaki $(\mathrm{M}=3.07, \mathrm{SD}=0.32)$. Data menunjukkan pemain bola baling perempuan lebih berorientasikan tugasan berbanding pemain bola baling lelaki.

Jadual 5: Ujian -t Perbezaan Orientasi Ego

bagi Pemain Bola Baling Lelaki dan Perempuan Bawah 18 Tahun

\begin{tabular}{|c|c|c|c|c|c|c|}
\hline & & & Ujian & Levene's & Persamaan & Min \\
\hline & & & Persamaan & Varian & Ujian -t & \\
\hline & & Nilai $\mathbf{F}$ & Signifikan & $\mathbf{T}$ & $\begin{array}{l}\text { Darjah } \\
\text { Kebebasan }\end{array}$ & $\begin{array}{l}\text { Tahap } \\
\text { signifikan }\end{array}$ \\
\hline & $\begin{array}{l}\text { Persamaan } \\
\text { Varian } \\
\text { Andaian }\end{array}$ & 0.85 & 0.36 & -2.42 & 190 & $0.02 *$ \\
\hline & $\begin{array}{l}\text { Persamaan } \\
\text { Varian } \\
\text { B/Andaian }\end{array}$ & & & -2.42 & 186.54 & $0.02 *$ \\
\hline
\end{tabular}

Analisis statistik kaedah Ujian-t Sampel Tidak Bersandar menunjukkan bahawa nilai t= $2.42(190)=0.01, p=0.02$ adalah signifikan. Keputusan ujian menunjukkan bahawa terdapat perbezaan yang signifikan dalam skor min corak orentasi matlamat berbentuk ego diantara pemain bola baling perempuan $(\mathrm{M}=2.62, \mathrm{SD}=0.25)$ dan pemain bola baling lelaki $(\mathrm{M}=2.53, \mathrm{SD}=0.30)$. 
Data menunjukkan pemain bola baling perempuan lebih berorientasikan ego berbanding pemain bola baling lelaki.

\section{Keagresifan}

Pernyataan yang telah diubahsuai merupakan situasi yang diberikan oleh pentadbir ujian kepada responden. Bahagian ini dijawab oleh reponden setelah tamat perlawanan. Tujuan situasi ini diberikan adalah untuk mengkaji tahap keagresifan pemain.

Jadual 6: Analisis Peratus, Min dan Sisihan Piawai Item Tahap Keagresifan bagi Pemain Bola Baling Lelaki dan Perempuan Bawah 18 Tahun

\begin{tabular}{lcc}
\hline Keagresifan & Nilai & Peratus (\%) \\
\hline Lelaki & 96 & 47.7 \\
\hline Perempuan & 96 & 52.3 \\
\hline
\end{tabular}

Jadual di atas merujuk kepada tahap keagresifan pemain bola baling lelaki. Analisis yang digunakan merupakan analisis peratus bagi mengenalpasti tahap keagresifan. Dapatan menunjukkan pemain bola baling perempuan lebih cenderung bertindak agresif dengan memilih untuk kemungkinan untuk menolak pihak lawan sebanyak 52.3 peratus berbanding pemain bola baling lelaki iaitu sebanyak 47.7 peratus.

Jadual 7: Analisis Min dan Sisihan Piawai Item Individu Utama Mempengaruhi Tindakan Agresif bagi Pemain Bola Baling Lelaki Bawah 18 Tahun

\begin{tabular}{lll}
\hline & $\mathrm{N}$ & Min (SP) \\
\hline Sahabat karib & 96 & $3.80(0.77)$ \\
Pemain terbaik pasukan & 96 & $3.59(0.92)$ \\
Ketua pasukan & 96 & $3.52(1.09)$ \\
Jurulatih/guru & 96 & $3.47(0.90)$ \\
Pemain terkenal/popular & 96 & $3.18(1.23)$ \\
Ibu bapa & 96 & $3.10(1.10)$ \\
\hline
\end{tabular}

Seterusnya, jadual 7 menunjukkan analisis deskriptif yang dijalankan untuk mendapatkan nilai min dan sisihan piawai bagi situasi yang terdapat di dalam soal selidik JAMBYSQ. Nilai min bagi individu yang mempengaruhi tindakan agresif dalam kalangan pemain bola baling lelaki telah direkodkan mengikut kedudukan yang tertinggi hingga yang terendah. Data menunjukkan "Sahabat karib" memainkan peranan yang besar untuk berlakunya tindakan agresif pemain sekiramya dipengaruhi $\mathrm{M}=3.80$ ( $\mathrm{SP}=0.77$ ). Yang kedua tertinggi adalah "Pemain terbaik pasukan" $\mathrm{M}=3.59$ ( $\mathrm{SP}=0.92$ ). Yang ketiga tertinggi mencatat, "Ketua pasukan" $\mathrm{M}=3.52$ ( $\mathrm{SP}=1.09)$ sebagai 
penyumbang kepada tindakan agresif sekiranya diminta berbuat demikian. Seterusnya, "Jurulatih/guru" M=3.47 (SP=0.90), "Pemain terkenal" M=3.18 ( $\mathrm{SP}=1.23$ ) dan "Ibu bapa" berada di tangga tiga yang terendah. Namun begitu, tetap menyumbang kepada berlakunya tindakan agresif sekiranya diminta berbuat demikian.

Jadual 8: Analisis Min dan Sisihan Piawai Item Individu Utama Mempengaruhi Tindakan Agresif bagi Pemain Bola Baling Perempuan Bawah 18 Tahun

\begin{tabular}{lll}
\hline & $\mathrm{N}$ & Min $(\mathrm{SP})$ \\
\hline Sahabat karib & 96 & $3.92(0.59)$ \\
Jurulatih/guru & 96 & $3.15(0.93)$ \\
Ibu bapa & 96 & $3.14(0.93)$ \\
Pemain terkenal/popular & 96 & $3.10(1.06)$ \\
Ketua pasukan & 96 & $2.86(1.08)$ \\
Pemain terbaik pasukan & 96 & $2.83(1.06)$ \\
\hline
\end{tabular}

Nilai min bagi individu yang mempengaruhi tindakan agresif dalam kalangan pemain bola baling perempuan juga telah direkodkan mengikut kedudukan yang tertinggi hingga yang terendah. Data menunjukkan "Sahabat karib" memainkan peranan yang besar untuk berlakunya tindakan agresif pemain sekiramya dipengaruhi $\mathrm{M}=3.92$ ( $\mathrm{SP}=0.59$ ). Yang kedua tertinggi adalah "Jurulatih" $\mathrm{M}=3.15$ (SP=0.93). Yang ketiga tertinggi mencatat. "Ibu bapa" $\mathrm{M}=3.14$ ( $\mathrm{SP}=0.93$ ) sebagai penyumbang kepada tindakan agresif sekiranya diminta berbuat demikian. Seterusnya, "Pemain terkenal/popular" M=3.10 (SP=1.06), "Ketua Pasukan" M=2.86 (SP=1.08) dan "Pemain terbaik pasukan" berada di tangga tiga yang terendah. Namun begitu, tetap menyumbang kepada berlakunya tindakan gresif sekiranya diminta berbuat demikian.

\section{Perkaitan Corak Orientasi Matlamat dan Keagresifan}

Jadual 9: Skala Kekuatan Korelasi

\begin{tabular}{ll}
\hline Nilai Korelasi $(\mathrm{r})$ & Pengertian Deskriptif \\
\hline $\mathrm{r}<0.20$ & Sedikit, Hampir diabaikan Perhubungan \\
$0.20 \leq \mathrm{r} \leq 0.40$ & Korelasi Rendah \\
$0.40 \leq \mathrm{r} \leq 0.70$ & Korelasi Sederhana \\
$0.70 \leq \mathrm{r} \leq 0.90$ & Korelasi Tinggi \\
$0.90 \leq \mathrm{r} \leq 1.00$ & Sangat Tinggi Korelasi \\
\hline
\end{tabular}

Sumber : Khairudin (2012). Perkaitan orientasi matlamat terhadap keagresifan ketara pemain bola sepak bawah 15 dan bawah 18 MSSM. Tesis sarjana yang tidak diterbitkan, Perak. Universiti Pendidikan Sultan Idris 
Jadual 10: Perkaitan Corak Orientasi Matlamat dan Keagresifan bagi Pemain Bola Baling Lelaki Bawah 18 Tahun

\begin{tabular}{lll}
\hline Keagresifan & $(\mathrm{r})$ & $\mathrm{P}$ \\
\hline Orientasi Ego & 0.394 & 0.039 \\
Orientasi Tugasan & 0.705 & 0.088 \\
\hline Signifikan pada aras $\mathrm{p}<0.01$ (2 tailed) & &
\end{tabular}

Jadual 10 adalah analisis kajian pemain bola baling lelaki menunjukkan terdapat hubungan signifikan yang rendah di antara orientasi ego dengan keagresifan iaitu $r=0.394, p<0.039$. Manakala perkaitan antara orientasi tugasan dengan keagresifan pula menunjukkan terdapatnya hubungan signifikan yang tinggi iaitu $\mathrm{r}=0.705, \mathrm{p}<0.088$.

Jadual 11: Perkaitan Oriemtasi Matlamat dan Keagresifan bagi Pemain Bola Baling Perempuan Bawah 18 Tahun

\begin{tabular}{lll}
\hline Keagresifan & $(\mathrm{r})$ & $\mathrm{P}$ \\
\hline Orientasi Ego & 0.951 & -0.006 \\
Orientasi Tugasan & 0.706 & 0.039 \\
\hline ignifikan pada aras $\mathrm{p}<0.01$ (2 tailed) & &
\end{tabular}

Jadual 11 merupakan analisis kajian pemain bola baling perempuan menunjukkan terdapat hubungan signifikan yang sangat tinggi di antara orientasi ego dengan keagresifan iaitu $\mathrm{r}=0.951$, $\mathrm{p}<-0.006$. Manakala perkaitan antara orientasi tugasan dengan keagresifan pula menunjukkan terdapatnya hubungan signifikan yang tinggi iaitu $r=0.706, p<0.039$.

\section{KESIMPULAN}

Sukan bola baling merupakan sukan yang sangat dikenali, digemari, dimainkan oleh sesiapa sahaja sama ada bermula pada akar umbi sehinggalah ke peringkat yang lebih professional. Dalam kajian ini, latar belakang responden memainkan peranan yang penting dalam menilai tahap pemahaman, perkaitan tindakan responden terhadap situasi dan perlakuan. Orientasi matlamat ialah kecenderungan seseorang atlet dalam mengkonseptualisasikan kejayaan atau pencapaian dalam sukan dari aspek peribadi dan hubungannya dengan orang lain (Zali, 2006). Hasil dapatan kajian kecenderungan orientasi matlamat pemain bola baling lelaki dan perempuan Negeri Sembilan adalah berorientasikan tugasan berbanding ego. Berdasarkan analisis keagresifan, dapatan 
menunjukkan atlet bola baling perempuan lebih cenderung melakukan keagresifan berbanding atlet bola baling lelaki. Kajian ini disokong oleh Shojaie et al (2004) ke atas 1531 atlet dari pelbagai sukan yang terdiri daripada pemain lelaki dan perempuan. Hasil dapatan kajian menunjukkan pemain perempuan lebih bermain secara agresif berbanding pemain lelaki. Secara kesimpulannya, hasil analisis menunjukkan bahawa atlet yang mempunyai corak orientasi matlamat yang tinggi memberi pengaruh yang besar terhadap pencapaian prestasi atlet bola baling lelaki dan perempuan bawah 18. Namun, corak kebimbangan (kognitif dan somatik), keyakinan diri dan tindakan agresif pula menunjukkan pengaruh yang sebaliknya terhadap pencapaian prestasi atlet tersebut.

\section{RUJUKAN}

Baumgartner, T.A., \& Hensley, L.D., (2006). Conducting and reading research in health and human performance $\left(4^{\text {rd }}\right.$ ed.). New York NY: Mc Graw Hill

Duda, J.L. \& Nicholls, J.G (1989). The Task and Ego Orientation in Sport Questionaire. Psychometric Properties. Unpublished manuscript.

Gill, D.L., (2000). Psychological Dynamics of Sport and exercise (2 ${ }^{\text {nd }}$ ed.). Champaign, III: Human Kinetics.

James, E.Z., \& David J.M., (2012). Sport Theraphy (Handbook of Sport Medicine \& Science). England : John Wiley \& Sons Ltd.

Junge, W., Sielaff, H. \& Engelbrecth, S. (2009). Torque generation and elastic power transmission in the rotary FOF1-ATPase. Nature, 459, 364-370.

Nathan, S. (2016). Badminton instructional in Malaysian schools: a comparative analysis of TGfU and SDT pedagogical models, SpringerPlus,5 (1215), 1-14

Shaharudin Abd Aziz (1998). Aggressive Tendencies in Malaysian youth soccer: An examination of individual and contextual factors. Tesis PhD yang tidak diterbitkan. Iowa: The University of Iowa

Shojaie, McKenry \& Traclet et al (2004). Argument, Aggression and Conflict : New Direction in Theory and Research. Routlegde, United Kingdom.

Silva, F. (1992). Assessing the child and adult personality: A decade of research. Personality and Individual Differences, 13, 1163 - 1181.

Weinberg, R.S., \& Gould, D (2003). Foundation of sport and exercise psychology ( ${ }^{\text {rd }}$ ed.). Champaign, III: Human Kinetics.

Zali A. Rahman, (2006). Orientasi matlamat pencapaian akademik \& sukan dalam kalangan atlet muda. Institut Perguruan Temenggung Ibrahim, Johor Bahru.

- Siti Aishah Md Yusop,

Fakulti Sains Sukan dan Kejurulatihan,

Universiti Pendidikan Sultan Idris, Tg Malim,

Perak, Malaysia

Email: sha84_inspiron@yahoo.com 